\title{
Diários no sentido irrestrito do termo: memórias virtuais de cidades reais
}

\section{Bianca Freire-Medeiros, Palloma Menezes e Fernanda Nunes}

\section{Resumo}

Promover viagens a localidades associadas à pobreza em diversas partes do mundo tornou-se um negócio lucrativo que provoca debates éticos em torno da associação entre lazer e miséria. Muitos dos que consomem a pobreza como atração turística não estão alheios a esses debates e fazem questão de tornar públicas suas reflexões sobre 0 tema em travelblogs. Neste artigo são examinados os aspectos imagéticos e discursivos de quatro blogs que narram experiências de contato com a pobreza turística em duas localidades distintas: Rocinha (Rio de Janeiro, Brasil) e Soweto (Joanesburgo, África do Sul). 0 objetivo mais geral é mostrar os impactos que a experiência de turismo em localidades pobres gera na imagem de cidade que esses turistas produzem.

\section{Palavras-chave}

Turismo. Pobreza. Travelblogs. Rocinha. Soweto.

\section{Bianca Freire-Medeiros I freiremed@hotmail.com} Doutora em História e Teoria da Arte e da Arquitetura pela Binghamton University, SUNY. Pesquisadora da Fundação Getulio Vargas - FGV.

\section{Palloma Menezes | pallomamenezes@hotmail.com}

Mestranda em Sociologia pelo Instituto Universitário de Pesquisas do Rio de Janeiro - IUPRJ, Universidade Cândido Mendes.

\section{Fernanda Nunes | fernanda.fnunes@gmail.com}

Graduanda em Ciências Sociais pela Fundação Getulio Vargas e bolsista PIBIC/CNPq.

\section{Introdução}

Em fins dos anos 1960, era lançado Um diário no sentido restrito do termo, de Bronislaw Malinowski, o consagrado "pai da etnografia". Por iniciativa e decisão de sua esposa, as notas íntimas de Malinowski tornaram-se públicas e de imediato sacudiram o espaço acadêmic $0^{1}$. No diário, que cobre parte do trabalho de campo do antropólogo junto aos mailu e aos trobriandeses, o criador do método da observação participante emerge quase irreconhecível a seus leitores, acostumados com suas ponderações lúcidas e equilibradas². Ao longo de quase 300 páginas, Malinowski revela encantamentos, impaciências e sonhos obscenos; mostra-se seduzido pelos nativos, mas também cansado deles. Queixa-se da solidão, do mau-cheiro, da comida, do malestar típico do estado de suspensão entre duas culturas. Como é próprio dos diários íntimos, a escrita de si de Malinowski pressupunha, ressalta Geertz (1997), um público de apenas um indivíduo, uma tradução da alteridade vista como mensagem do eu para si mesmo - daí a 
ressalva que o título antecipa: "um diário no sentido restrito do termo".

Neste artigo, o foco recai sobre casos em que a escrita de si e a atividade de tradução da alteridade se materializam em diários no sentido irrestrito, ou seja, narrativas da experiência e dos acontecimentos vividos em contato com terras distantes concebidas por seus autores como narrativas públicas - são os chamados travelogues virtuais. Frustrações, seduções e estranhamentos diante do Outro podem até assumir um tom confessional ou introspectivo, mas desde o início são pensados como experiências a serem compartilhadas, muitas vezes antes mesmo do retorno do autor ao local de origem. Não raro, os turistas fazem propaganda de seus diários em outros sites, o que permite que não só amigos ou parentes acompanhem seu itinerário, mas também que pessoas que lhe são desconhecidas possam ler suas reflexões e fazer comentários sobre textos e fotografias.

Do vasto conjunto de diários de viagens que habita o espaço virtual, escolhemos aqueles que narram o contato com o que Freire-Medeiros (2007a) chama de pobreza turística - uma pobreza emoldurada, anunciada, vendida e consumida com um valor monetário definido no mercado turístico. Argumentamos que esse contato é vivenciado pelos turistas como condição de possibilidade não apenas de uma experiência de viagem singular, mas de revelação da cidade real.

A promoção de excursões a localidades associadas à pobreza e à segregação em diferentes níveis tornou-se um negócio lucrativo, provocando debates acalorados em ambientes diversos, tanto no domínio acadêmico quanto no seio da opinião pública. Esses debates, via de regra, giram em torno do problema ético do consumo da miséria e de sua reprodução fotográfica (FREIRE-MEDEIROS, 2007a; FREIREMEDEIROS et al, 2008). Muitos dos que consomem a pobreza como atração turística não estão alheios às polêmicas suscitadas, pelo contrário: ao tornarem públicas suas viagens a localidades em geral evitadas pelas elites autóctones, tomam parte dessa discussão e encorajam outros potenciais turistas a ingressar no mesmo tipo de experiência.

A seção que se segue oferece um breve exame das dinâmicas de interação e comunicação de

Valetta Malinowska justificou a polêmica iniciativa nos seguintes termos: "Reconheço que, para alguns, um diário é algo de natureza basicamente privada, e não deveria ser publicado [...]. Mas [...] cheguei à conclusão de que é muito mais importante dar aos atuais e futuros estudiosos e leitores das obras antropológicas de Malinowski essa visão direta de sua personalidade íntima, e de sua forma de viver e pensar durante o período de seu mais importante trabalho de campo, do que trancafiar esses sucintos diários em um arquivo" (apud MALINOWSKI, 1997, p.13).

Para James Clifford, Os argonautas do Pacífico Ocidental - considerado a obra inaugural da tradição etnográfica - e 0 Diário no sentido restrito do termo devem ser lidos como textos complementares ou mesmo como um único texto expandido. 0 diário de Malinowski, a despeito de seus rasgos de profundo etnocentrismo, constituiria "um inventivo texto polifônico, e um crucial documento na história da antropologia porque revela a complexidade dos encontros etnográficos" (CLIFFORD apud FIRTH, 1989). Clifford destaca, portanto, a contribuição que o texto de Malinowski, ao transcrever a complexa experiência de deslocamento e de contato com a alteridade, traz à teoria e ao fazer antropológicos. 
dois sites de viagem que se encontram entre os mais procurados pelos interessados no turismo de pobreza. Na seção três, examinamos os aspectos imagéticos e discursivos de quatro travelblogs ${ }^{3}$ que narram memórias de viagem a duas localidades sobre as quais as pesquisadoras vêm refletindo de maneira sistemática4: Rocinha, a "favela turística" por excelência"; e Soweto, território estigmatizado que, com o fim do apartheid ${ }^{6}$, tornou-se um dos destinos turísticos mais visitados da África do Sul. Encerramos compartilhando algumas reflexões sobre a imagem de cidade expressa nesses diários virtuais.

\section{Memórias virtuais nos travelblogs}

Uma busca com a ferramenta Google nos dá um retorno de mais de 6 mil resultados para blogs de viagem em português e aproximadamente 8.400.000 em inglês. A maioria desses blogs, quer brasileiros ou estrangeiros, estão hospedados em sites gratuitos ao usuário. Os blogs que escolhemos como plataforma de reflexão para este artigo foram localizados em dois dos sites de viagem mais populares: TravelBlog e I GO U GO?

\section{0 site TravelBlog é promovido por seus} organizadores como o único diário de viagens on-line grátis para viajantes do mundo todo. No ar desde 2002, oferece um conjunto de ferramentas que possibilita a elaboração de diários virtuais passíveis de serem compartilhados de forma ágil por meio de uma lista de distribuição automática definida e atualizada pelo usuário. 0 site incentiva ainda seus membros a criarem links para sites considerados úteis e a formularem "guias" com 0 intuito de ajudar futuros viajantes. A página pode ser acessada no mundo inteiro, sem nenhum tipo de restrição, o que permite que os usuários atualizem seus diários on-line de onde quer que estejam.

Apesar de não haver consenso, costuma-se denominar blog um registro cronológico e freqüentemente atualizado de opiniões, sentimentos, fatos, imagens ou qualquer outro tipo de conteúdo que 0 autor queira disponibilizar na Internet para que qualquer pessoa, conhecida ou desconhecida, tenha acesso - um diário virtual e público. Uma das vantagens das ferramentas de blog é permitir que mesmo os usuários sem conhecimento técnico especializado publiquem tanto textos como imagens. (SCHITTINE, 2004; MÁXIMO, 2007).

Este artigo deriva das reflexões contidas nos projetos de pesquisa "Touring Roverty in Buenos Aires, Johannesburg and Rio de Janeiro" (financiado pela Foundation for Urban and Regional Studies - FURS) e "A Construção da favela carioca como destino turístico" (financiado pelo CNPq). Ambos os projetos são coordenados por Bianca Freire-Medeiros e contaram, desde o início, com a participação de Palloma Menezes, primeiro na qualidade de bolsista PIBIC/UERJ, e hoje como interlocutora privilegiada. Fernanda Nunes integra a equipe desde 2006 como bolsista PIBIC/CNPq.

A Rocinha recebe turistas regularmente desde 1992 e foi reconhecida como ponto turístico oficial da cidade em 2006.

Regime de discriminação racial implementado pelo Partido Nacional na África do Sul entre 1948 e 1990. A catalogação racial de toda criança recém-nascida, a Lei de Repressão ao Comunismo e 0 incentivo à divisão tribal com a formação dos Bantustões, em 1951, foram os grandes pilares do apartheid. Com poucas exceções, o espaço urbano foi designado "apenas para brancos" (whites only), permitindo ao Estado evitar o surgimento de bairros racialmente integrados (CHRISTOPHER, 1987; PARNELL, 2003).

Segundo 0 site <http://www.alexa.com>, que mede a audiência de sites do mundo todo, 165 sites hospedam blogs de viagens, entre os quais o mais acessado é o Virtual Tourist que, por não disponibilizar nenhum blog sobre viagem a Rocinha, foi desconsiderado neste artigo. TravelBlog é o segundo mais acessado, enquanto I GO U GO aparece em quarto lugar. 
0 TravelBlog foi fundado por Alistair Watters, empresário inglês que, como ele mesmo conta, trabalhou nas maiores companhias de informação tecnológica em Londres. Segundo Watters, a idéia de criar 0 site surgiu de uma necessidade pessoal de contato e também de distinção: "I started TravelBlog to keep my family and friends in touch with my journey, and make as many of my former co-workers as jealous as possible. I've updated the site from all four corners of the globe, and it's pretty much taken over my life now $[\ldots]^{8 \prime}$. Atualmente 0 TravelBlog possui mais de 80.000 membros regulares e todos os dias cerca de 100 novos membros passam a fazer parte do site. Hospedam-se ali mais de 2 milhões de fotos e 30.000 mapas.

Também com o intuito de ajudar e inspirar futuros viajantes a escolherem seus destinos turísticos, o I GO U GO disponibiliza fotos e textos que contam as experiências de viagem de turistas de várias partes do mundo. Criado dois anos depois do TravelBlog e duplamente premiado - em 2004 na categoria "Best U.S. Travel Site" pela Webby Award e, em 2006, como "Best Travel Site" pelo prestigioso site da Forbes — o I GO U GO detém informações acerca de 5.500 destinos diferentes e mais de 300.000 turistas já compartilharam ali suas idéias, opiniões e fotografias ${ }^{9}$.
Mais do que um simples roteiro, pretende oferecer gratuitamente "a library of honest opinions, tips, and experiences that you won't find in any guidebook". Como o próprio site informa, trata-se de um serviço voltado para um público amplo, que inclui desde viajantes a empresários que buscam informações sobre turismo. Para cada destino turístico, os membros do I GO U GO podem compartilhar pequenas análises sobre hotéis, atrações, restaurantes e entretenimento noturno. Mas, assim como no TravelBlog, há também a possibilidade de escrever histórias longas e detalhadas sobre a viagem, criar seu próprio diário e disponibilizar fotografias. Em ambos os sites, o público é majoritariamente composto por turistas jovens que se enquadram no segmento "low budget".

A cada semana os editores do I GO U GO elegem os dez "pacotes" turísticos que estão "mais em conta". Há, inclusive, premiações (U G0! Award) aos membros mais acessados ou bem votados e um "hall da fama" dedicado aos turistas "exemplares", isto é, aqueles que mais contribuem anualmente com 0 site. Para ilustrar, há fotografias e opiniões dos turistas "famosos" do blog. Shady, uma das freqüentadoras do "hall da fama", revela por que escolheu o I GO U GO e ressoa o argumento de vários usuários desse tipo de serviço:

Esta e as demais citações foram mantidas na língua original para que seja perceptível o esforço empreendido pelos turistas de tradução da cultura alheia. 
"It's nice to know that the articles I write are read by like-minded people and actually help people plan and improve their holidays. Most of the articles I write relate to my very own experiences, and there aren't many websites other than personal blogs that allow such long entries. Therefore, I GO U GO is perfect for developing my writing skills, interacting with other writers, and allowing my stories to be told to a global audience".

Como apontado por Shady, não apenas 0 intercâmbio entre os que valorizam a viagem como prática em que se combinam lazer e refinamento do self, mas também a visibilidade global que seus textos e experiências alcançam parecem ser, de fato, os grandes motivadores para que os turistas publiquem seus diários virtualmente. Por certo a publicização de diários de viagens antecede em muito 0 advento da Internet e é prática quase tão antiga quanto a própria viagem. Ultrapassa as intenções deste artigo examinar as diferenças e aproximações inerentes à publicação de diários de viagens nos formatos impresso, fílmico ${ }^{10}$ ou digital. Mas vale notar que, independente do suporte, a narrativa de viagem persegue a tradução de um determinado lugar para 0 idioma cultural do autor e de seus pares, o que inevitavelmente implica, por um lado, grandes perdas de significado e, por outro, uma rica reposição de valores simbólicos. Na seção que se segue, estaremos menos interessadas em examinar se os autores dos blogs conseguiram aprender a pluralidade de significados inscrita em territórios como Rocinha e Soweto, e mais focadas em compreender como o contato com a pobreza turística se traduz, por meio de texto e imagem no espaço virtual, em uma experiência de "cidade real".

\section{Viagens ao coração da cidade}

Viajamos não apenas porque nos interessa conhecer determinado destino, mas igualmente para nos posicionarmos face à lógica de atribuição de status da classe ou do grupo social a que pertencemos. "Trata-se de uma aprendizagem relacional", argumentam Carneiro e Freire-Medeiros (2004), "em que a transação cultural com 0 outro permite estabelecer uma melhor definição de si e reforçar o sentimento de pertencimento ao seu próprio grupo" (p. 105).

Há muito as viagens de lazer operam como elemento de distinção, mas com as segmentações do mercado turístico, esse tipo de deslocamento tornou-se um veículo ainda mais poderoso de comunicação dos princípios de pertencimento e diferença. Cresce o número dos chamados pós-turistas que, política e ecologicamente corretos, evitam a todo custo "o lazer de ir ver 0 que se tornou banal", para usarmos a expressão de Guy Debord (2003). Reproduz-se no âmbito 
do turismo aquilo que ocorre em tantos outros campos: uma vez que os grupos de mais baixo status se apoderam da viagem de lazer como um bem, resta aos demais segmentos "investir em novos bens a fim de restabelecer a distância social original" (Featherstone, 1995, p. 38). No processo, localidades "marginais" ao mercado convencional são reinventadas como destino turístico e disponibilizadas para consumo de um público ávido por experiências que o coloquem um degrau acima na hierarquia de status dos "world travelers" (HUTNYK 1996; FREIREMEDEIROS et al., 2008).

0 consumo da pobreza pela via do turismo transmuta-se, por paradoxal que possa parecer, em um elemento de distinção social. Essa pobreza turística, por um lado, beneficia-se dos fluxos transnacionais de capital, de imagens midiáticas e de pessoas que transformam a alteridade em mercadoria; por outro, capitaliza a onda do poor chic - "a set of fads and fashions that make stylish or recreational 'fun' of poverty" (HALNON, 2002, p. 513) -, ao mesmo tempo em que ajuda a alimentá-la. Os turistas, ao consumirem os objetos e práticas associados aos "pobres", não querem ser como eles, mas antes consumir a diferença através de seus símbolos. Levas e levas de turistas dirigem-se não apenas à Rocinha e a Soweto, mas também à Cova da Moura, "bairro africano" e "marginal" em Lisboa, e a Dharavi, tida como a maior slum da Ásia, localizada no centro de Mumbai ${ }^{11}$ - para citarmos apenas alguns. Não há dúvida de que se trata de experiências bastante heterogêneas (FREIREMEDEIROS, 2007b), mas 0 fato é que estamos diante de um mercado globalmente consolidado.

Esses tours vêm sendo promovidos por ONGs, agências de turismo e/ou agentes públicos, os quais defendem a prática do turismo em áreas pobres com base em sua suposta capacidade de incrementar o desenvolvimento econômico, a consciência social dos turistas e a auto-estima das populações receptoras. Seus críticos apontam para 0 fato de que os moradores das localidades visitadas não usufruem em pé de igualdade dos benefícios gerados e que, menos do que conscientização política ou social, o que as visitas motivam são atitudes voyeuristas diante da pobreza e do sofrimento (FREIRE-MEDEIROS 2007a; FREIREMEDEIROS et al., [documento eletrônico]). A experiência de consumo da pobreza turística, é importante retermos, persegue um fino equilíbrio entre gozo e comiseração. Como nos lembra Bourdieu (2007), a "nova burguesia" universitários que atingiram posições de poder ainda jovens nas empresas mais importantes e modernas - constrói o cerne de sua identidade contrapondo-se à burguesia de tradição, que baseia sua vida na moralidade do dever. Se a 
velha burguesia passa suas "férias nas cidades hidrominerais" e sente "medo do prazer", a nova burguesia propõe uma moral do "dever de prazer que leva a experimentar como um fracasso, propício a ameaçar a auto-estima, qualquer impotência em 'divertir-se', to have fun" (BOURDIEU, 2007, p. 345). 0 prazer, além de autorizado, é exigido, ainda que ele derive da contemplação da miséria alheia.

Mas, num momento em que cidadania e consumo se atravessam e se encompassam de maneira tão contundente (CANCLINI, 1999), exige-se do sujeito uma atitude reflexiva e autocrítica diante do objeto que deseja consumir e das práticas sociais que envolvem sua aquisição. 0 turista inglês, que assina sob o pseudônimo de WitlessWanderer $^{12}$, dá início a seu travelblog ${ }^{13}$ questionando a própria existência da pobreza turística: "I'm not a fan of poverty tourism, which I think demeans everyone involved. After the patronising ' $\mathrm{Oh}$... so you're poor?', there is always the unspoken coda 'Glad I'm not."'.

Essa estratégia de reação antecipada a críticas é acionada por WitlessWanderer e pelos demais turistas que compartilham suas impressões nos blogs ou com quem conversamos ao longo da pesquisa ${ }^{14}$. Apesar de titubeantes e receosos de início, são unânimes em dizer que o passeio, diferente do que imaginavam, proporcionou-lhes uma outra visão da favela. WitlessWanderer resume: "Where I feel this tour differed is that as well as recognising the obvious negative elements, there is also a strong emphasis on the positive aspects such as the creativity and skill present in the favelas if it is only given an opportunity to express itself". Diante das saídas criativas dos que vivem em uma realidade tão adversa, o turista se sente ao mesmo tempo diminuído e em êxtase: "If it helps, I did feel thoroughly worthless by the end of the trip and utterly in awe of the incredible work that these people have done for years on end". É 0 contato em primeira mão com a adversidade que garante a WitelessWanderer - e a muitos outros turistas - uma experiência transformadora do self. Voltaremos a essa questão mais adiante.

WitlessWanderer, que visitou a Rocinha no verão de 2005 , descreve a origem das favelas e convida o leitor a espantar-se com seu número e com o tamanho da população que habita esses territórios. Como nos demais diários virtuais sobre visitas à Rocinha, as favelas são descritas como territórios marginais à cidade formal, quatro fotos ao passeio pela favela: "Children of the Favela at the school"; "Rocinha Favela. Nestled against one of Rio's hills"; "The Crowded Streets. Layer upon layer"; "Poor and Rich side by side. Rocinha and Vidigal”. Disponível em: <www.igougo.com/ story-s1226540-Rio_de_Janeiro-Favela_Tours.html>. Acesso em: 14 ago. 2008.

A pesquisa "A Construção da Favela Carioca como Destino Turístico" vem examinando, desde fevereiro de 2005, o processo de conversão da favela em atração turística do ponto de vista dos agentes promotores, dos moradores locais e dos turistas. 
regiões praticamente desconhecidas pelos turistas e pelos próprios brasileiros: "It's a complete other world that few tourists and indeed few Brazilians visit. But you can. [...] don't worry, most of the time you are driven around in a van as your guide, Christina, shouts hellos to passing friends".

Diferente do que WitlessWanderer imagina, a Rocinha recebe bem mais do que uns poucos turistas: são cerca de três mil visitantes por mês. Atuam regularmente na localidade sete agências com cadastro junto à Riotur, além de taxistas $\mathrm{e}$ guias particulares. Se o nosso andarilho errante quisesse, poderia ter feito o passeio de jipe ou de moto, poderia ter almoçado na movimentada Rua 1 - onde souvenires produzidos por moradores locais são adquiridos pelos turistas (FREIREMEDEIROS et al, [documento eletrônico]), ou ainda ter conhecido a favela à noite no pacote Rocinha by Night. Para qualquer uma dessas opções de passeio, a duração e o preço costumam ser os mesmos: de três a quatro horas, $\mathrm{U} \$ 35,00$ por pessoa.

"I'm not sure I quite knew what I was getting myself into when I called and booked the tour for that afternoon", encerra WitlessWanderer, "but I'm glad I did. Fun isn't the word, but it was one of the most interesting tours I've done and showed the Rio beyond the beaches". A idéia de que não somente a subjetividade do turista ou a favela emergem diferentes ao final do passeio, mas que o próprio Rio de Janeiro se revela em sua autenticidade plena, é corroborada por Lauren Levine, autora do blog "The real Rio": "there really is even more to understand about Rio than meets the eye. Sure - I spent every single day at the beach in Ipanema [...], then partied with friends by night. But that wasn't the part of Rio that stayed with me. It was the 'other Rio' I saw that will likely affect my memory forever".

Mas, assim como WitlessWanderer, Lauren recorda as hesitações que antecederam o passeio: "I was at first concerned about it, but when I heard from everyone that it is absolutely safe [...], and from people who did it that it was great, I decided to sign up, and wasn't sorry about it. Actually this tour was an experience which had the greatest impact on me, since the beginning of my travel". 0 compartilhamento da hesitação é tão recorrente e enfático nos blogs que nos provoca a refletir sobre as ansiedades que rondam a pobreza turística e que não parecem limitar-se ao território da favela ou à questão da segurança. Ao longo da pesquisa, percebemos que as contradições intrínsecas à construção, comercialização e manutenção de localidades turísticas de fato tornam-se mais complexas em todos os casos em que a pobreza é a atração central. Visto que o mercado - território das relações impessoais e da lógica instrumental por excelência - não é naturalmente concebido como lugar adequado à expressão da comiseração ou da solidariedade (ILLOUZ, 1997; ZELIZER, 2004), fazer da pobreza uma mercadoria, uma atração turística pela qual se cobra e se paga um preço fixo passa a ser facilmente avaliado como algo abjeto (FREIRE-MEDEIROS, 2007a). Por outro 
lado, as superposições entre sofrimento e lazer são recorrentemente concebidas pela moralidade ocidental como a-gramaticais (STONE, 2006; STONE; SHARPLEY, 2008). Não surpreende, portanto, que aqueles que optam por consumir a favela turística hesitem em um primeiro momento. É importante convencer - a si e aos demais que não se trata de um exercício voyerístico, mas de um ato ético e solidário. Na conclusão, retomaremos essas questões. Por agora, seguimos 0 nosso tour com Lauren.

As memórias virtuais da jovem californiana, que se apresenta como uma apaixonada por viagens e antropologia, desvendam o 'outro Rio' acionando, primeiramente, as imagens da cidade que circulam mundo afora: praias, biquínis, carnaval, Copacabana, samba e sol. Porém, como ela diz, há mais a descobrir sobre 0 Rio do que os olhos podem ver. 0 contato com a favela proporciona uma experiência que ultrapassa a dimensão visual e se expressa na mobilização de vários sentidos e sentimentos. 0 medo é um deles: "On the day that I visited, I was asked to roll down the window of the van I was in so the drug lords could see that I was a tourist and not a member of a rival gang. Just two weeks prior, a gang had used the same style tourist van to smuggle themselves in and a bloody gun fight ensued".
Apesar de a maioria das agências evitar as ruas em que há venda de drogas ilícitas e recomendar que não sejam tiradas fotos de pessoas armadas, o tráfico e suas práticas violentas são temas inevitavelmente abordados durante os passeios. Nesse sentido, os agentes turísticos capitalizam, em maior ou menor medida, a ansiedade contemporânea entre liberdade e segurança descrita por autores como Bauman (2001) e Giddens (1991), prometendo oferecer aos turistas um contato seguro com a violência armada. Em seu material publicitário, todas as agências se responsabilizam pela segurança de seus clientes e os incentivam a trazer suas câmeras fotográficas e filmadoras (FREIRE-MEDEIROS, 2007b).

0 'outro Rio' de Lauren é capturado visualmente em oito fotos ${ }^{15}$. A que abre 0 seu blog de viagem é esta: duas crianças abraçadas que ela supõe serem irmãos (Imagem 1). 0 menino percebe que está sendo fotografado, olha para câmera e sorri. Distraída, a menina tem uma das mãos na boca e parece não notar - ou pelo menos não se importar - em ser alvo das lentes fotográficas de Lauren. De fato, turistas e câmeras são presença tão recorrente no cotidiano da Rocinha que já não causam estranhamento na população local (MENEZES, 2007). 0s moradores sabem que

No blog, além das fotos de crianças (Siblings / Favela boy), há uma foto de uma senhora comprando carne (Meat Market Lady ...decisions, decisions!), outra de uma barraquinha no Largo do Boiadeiro (Hardware store in the favela), além de uma panorâmica (Favela homes ...And I thought we lived on top of each other in San Francisco) e de um close das casas da favela (A closer look). Foram também fotografados por Lauren um homem sorridente vendendo caranguejo (Crab Guy) e uma carcaça (Unidentified carcass ...even up close I have no idea what animal this is. So I just stuck to salads for awhile). Disponivel em: <http://www.travelblog.org/ South-America/Brazil/Rio-de-Janeiro/Rio-de-Janeiro/blog-46579.html>. Acesso em: 14 ago. 2008. Lauren tem também um website próprio (http://www.laurenlevine.com/Home.html), que ela convida os visitantes do TravelBlog a conhecerem. No site há fotografias das viagens que a americana fez entre 1996 e 2004. 0 uso das fotos neste artigo nos foi autorizado por cada um dos turistas. 


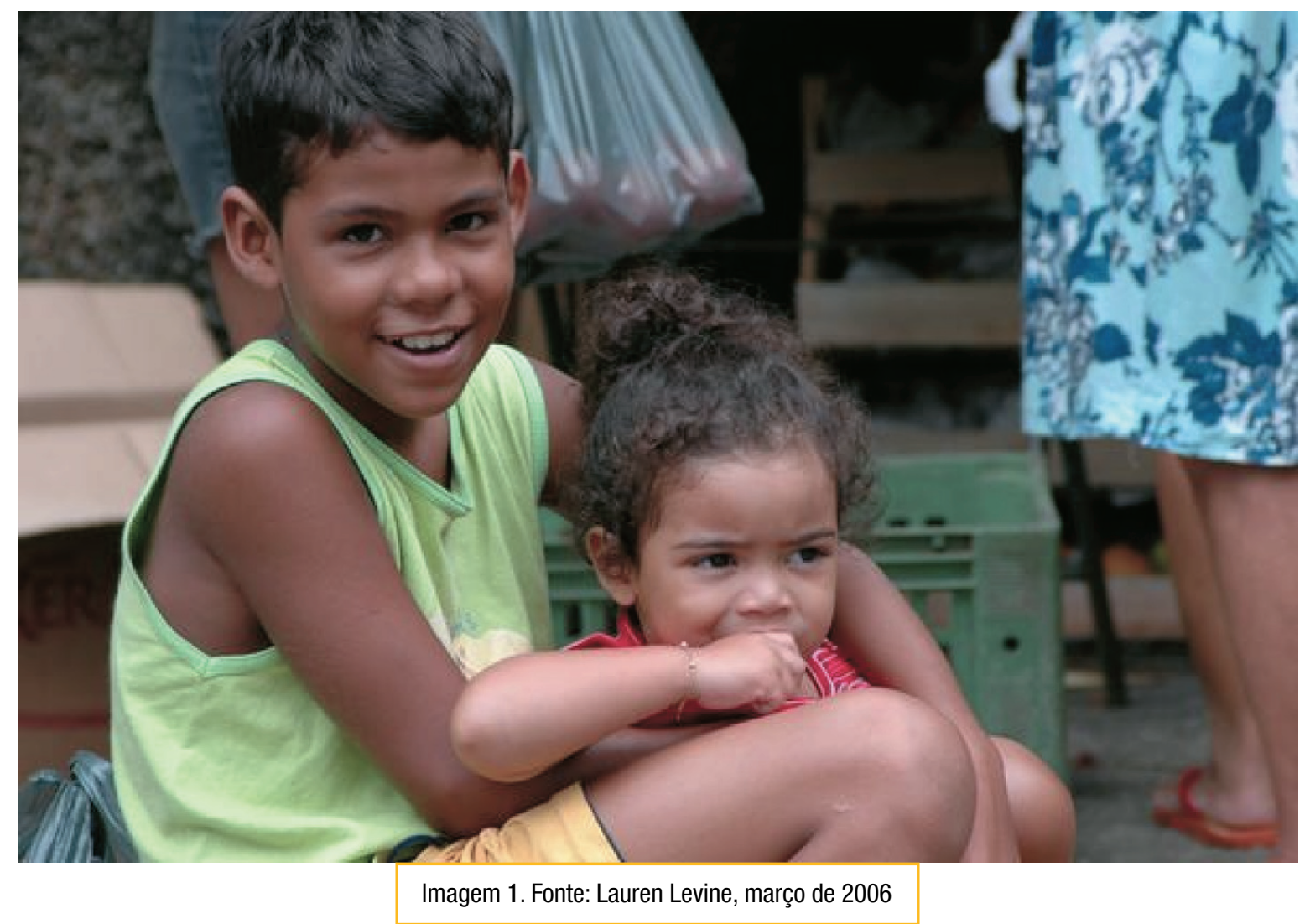

todos os dias algum turista - ou mais de um - irá smile emerge on their face as they say hello back. fotografar as crianças nas ruas e vielas da favela. Such lovely people... and with such unbelievable Poucos são os que reclamam de serem 0 alvo da circumstances they were dealt".

mira dos estrangeiros; as crianças em particular expressam, por meio das palavras que sabem falar em inglês ou de gestos, o desejo de serem fotografadas e instantaneamente verem suas poses sorridentes retratadas no visor das câmeras digitais.

"That being said, I very much enjoyed my time in the favela. The people are beautiful and their sense of community and family is humbling", conclui Lauren. E prossegue inserindo-se no quadro que descreve em tempo presente: "I love saying hello to every single person I pass, and then see a huge

Ao fim, parece emergir uma favela cuja geografia imaginativa remete a uma composição peculiar entre violência e solidariedade, pobreza e alegria. Se a favela vista da janela do hotel era apenas precariedade e ameaça, a favela vista "de dentro", a despeito dos estereótipos que persistem, torna-se menos redutível porque a pobreza não se revela nem absoluta nem deprimida. A cidade do Rio de Janeiro, por sua vez, quando vista pelos turistas a partir da favela ${ }^{16}$, emerge como um espaço em que se acomodam de forma

16 Todas as agências incorporaram em seus passeios o "momento laje": com o mar de casas a seus pés, os turistas confrontam a favela com seu entorno, as casas mal alinhadas com os edifícios luxuosos à beira do mar. 0s moradores que alugam suas lajes recebem das agências um valor fixo, algo em torno de R\$2,00 por turista. No caso de haver um "contrato de exclusividade" entre morador $\mathrm{e}$ agência, os guias já ficam em posse da chave da casa do morador e sobem com os turistas mesmo se o proprietário estiver ausente. 


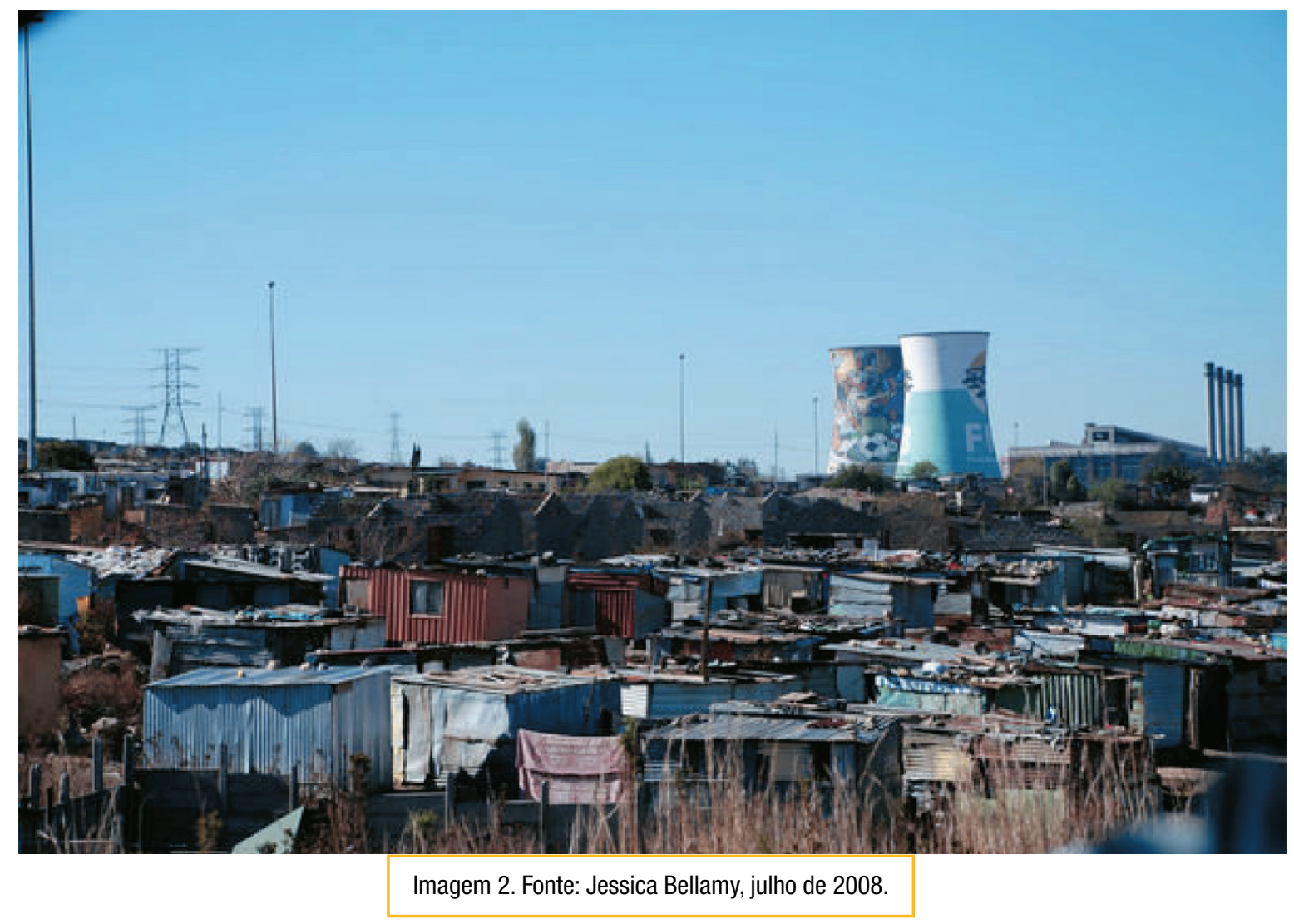

precária contradições e iniqüidades cujo sentido apenas com as torres de energia que se vêem ao

lhes parece escapar. Essa percepção da cidade fundo, mas, sobretudo, com o Maponya Mall, um como um espaço intrinsecamente ambíguo não shopping gigantesco inaugurado em setembro é exclusiva, contudo, ao Rio de Janeiro, como de 2007 e com as chamadas Torres Gêmeas de veremos a seguir.

Esta foi a foto escolhida pela turista Jessica Bellamy (Imagem 2) ${ }^{17}$ para introduzir suas memórias de viagem a Soweto. Como o título de seu travelblog antecipa - "Apartheid, Separation and History in South Africa" - e a foto ilustra, 0 tema central da narrativa de Jessica são os paradoxos e ambigüidades da sociedade sulafricana que lhe parecem encenados em toda sua plenitude no território de Soweto. Os barracos precários em primeiro plano contrastam não Soweto, conhecidas mundialmente a partir de sua inclusão no reality show Amazing Race da CBS.

Assim como a Rocinha é comercializada no mercado turístico como "a maior favela da América Latina", Soweto é recorrentemente apontada pelos agentes promotores do turismo como a township mais famosa do mundo (MABOGANE; CALLAGHAN, 2002), principal palco das lutas de resistência ao apartheid. Identificar as lógicas e as marcas desse regime de segregação racial e traduzi-las para os seus 
leitores - essa empreitada nada modesta é o que mobiliza Jessica e anima suas conversas com os moradores locais, guias turísticos e vendedores de souvenires. "You see for me, the racism and classicism (which still go hand in hand), and variance in economic prosperity was so readily apparent it was like a slap in the face", teoriza a jovem norte-americana. E completa: "The museums and documentaries don't talk about this". A experiência em primeira mão, mais uma vez, é o que garante a suposta apreensão pelo turista da verdadeira cidade - e por extensão de toda a cultura nacional. Em uma inversão metonímica, a parte explica o todo e as sociedades brasileira e sul-africana ganham inteligibilidade a partir de seus territórios mais segregados.

Mas enquanto o contraste entre "favela" e "cidade" parece ser a marca dos passeios à Rocinha, são as ambigüidades intrínsecas a Soweto que estruturam os tours promovidos pelas dezenas de agências que atuam na localidade. Em geral, começam por uma área chamada Diepkloof Ext onde vivem os famosos black diamonds - negros que conseguiram ascender economicamente e moram em casas de arquitetura sofisticada, bem equipadas e com alto valor no mercado imobiliário. Os tours seguem pelo Baragwanat Hospital ("o maior hospital do hemisfério sul"), pelas Twin Towers (as torres que vimos na foto de Jessica) e pelo Maponya Mall. Esse lado "desenvolvido" e "promissor" de Soweto é posto em contraste logo em seguida: metros à frente, os turistas são apresentados ao Kliptown Squatter Camp, um alojamento criado em 1903, onde várias famílias ainda compartilham um ambiente extremamente precário. Dependendo do nível de intimidade do guia com os moradores, é permitido aos turistas entrar nos pequenos cômodos e fotografar. Não parece ter sido o caso de Jessica, que clica Kliptown à distância ${ }^{18}$.

"I felt as far from the USA as I've ever felt, much farther than in a tent in the middle of the delta in Botswana", confessa Jessica. 0 jogo de oposições alcança aqui outra dimensão e coloca em contraste os supostos princípios de liberdade e igualdade da sociedade norteamericana e a segregação social e econômica persistente na África do Sul. Uma revelação tão poderosa parece ser a justificativa a posteriori para Jessica ter vencido a hesitação inicial em relação ao passeio: "Just where they are now, and how much they have to go is not as easy to answer, but I am wholly glad I visited the city, against conventional wisdom, as I feel that I have had a first hand, if short, education of the strides this country has made, is making and a tiny feel of what it is like on both sides of the wall and barbed wire fence."

Se as memórias virtuais da visita de Jessica a Soweto giram basicamente em torno da persistência do racismo, as do turista que 
escreve sob o pseudônimo de MikeIn Town ${ }^{19}$ estão centradas na tentativa de compreensão e tradução do apartheid em seu sentido mais amplo a partir daquele território específico: "Soweto is the largest township in South Africa. It was started by the blacks who migrated from rural areas to Johannesburg in search of work in the gold mines. Since apartheid laws forbade them from living in Johannesburg, they lived in singlesex hostels and squatter camps just outside the city. This community became known as Soweto (South Western Township)."

Com o título descontraído de "Jo'burg and the Burbs", o travelblog registra o passeio feito por MikeInTown e sua esposa em dezembro de 2006 na companhia de um guia "nativo": "We were fortunate to have an outstanding tour guide who has lived in Soweto all his life". Na maioria dos casos, agências externas administradas por brancos contratam guias negros, moradores do local, o que muitas vezes dá aos turistas a falsa impressão de que o dinheiro pago pelos passeios reverte em ganhos diretos para as townships.

"Our ride through this township was quite an eye-opening experience for me", afirma 0 turista afro-americano. E prossegue marcando 0 contraste entre as referências midíaticas, que reduzem Soweto a um território pobre e violento, e 0 encontro em primeira mão, que revela 0 local em sua complexidade: "Before this trip, the images I had seen of Soweto on TV were those of shanty towns, crime, and prostests. While we definitely saw our share of shanty towns and were told crime is still a major concern, we also saw some of the nicest neighborhoods".

Segundo nos conta MikeIn Town, o ponto alto de sua visita a Soweto foi a ida a Vilakazi Street, "the only street in the world to contain the homes of two Nobel Peace Prizes winners", em referência a Nelson Mandela e Desmond Tutu. Os artigos pessoais de Mandela, principalmente um cinturão que foi presente do boxeador Sugar Ray Leonard (Imagem 3), capturam a atenção do turista.

No travelblog há outras seis fotografias, porém nenhuma delas foca pessoas. De fato, 0 interesse de MikeInTown parece voltarse para o contraponto entre "shanty towns" e "neighborhood", que aparece sintetizado e ilustrado nas fotografias das residências correspondentes a cada um desses espaços. Em uma das fotos vemos barracos espalhados em meio a uma vegetação seca. Como não há muros, vemos as roupas estendidas em um varal improvisado. A fotografia vem acompanhada da seguinte legenda: "The shanty towns of Soweto illustrate the desperate poverty of many of its residents." Na foto seguinte encontramos casas bem pintadas, com telhados coloridos, muro e jardins bem cuidados: 


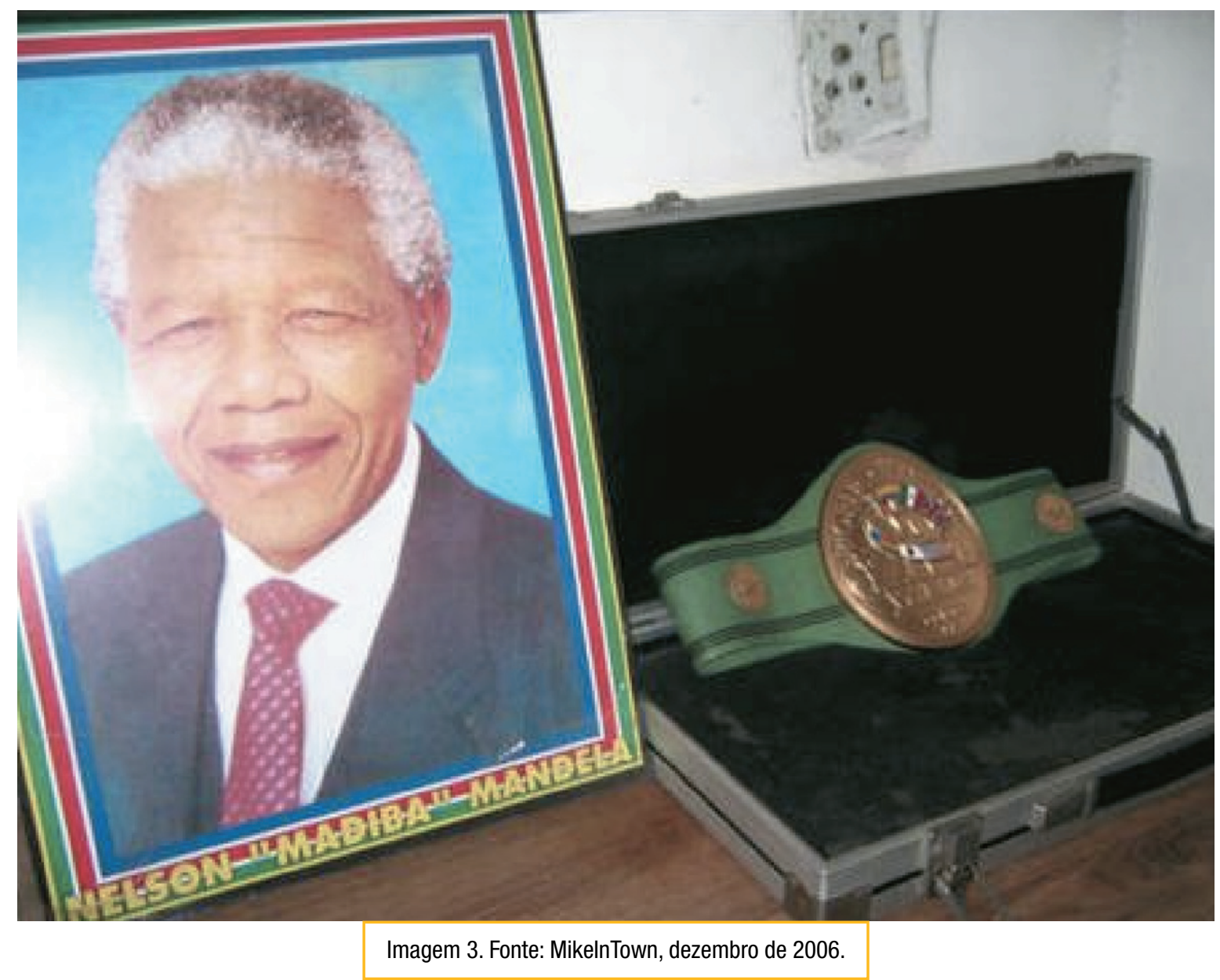

"Soweto does not consist of all shanty towns. There are nice neighborhoods such as this one".

Jessica, MikeInTown e sua esposa foram apenas três das centenas e centenas de turistas que chegam diariamente e das mais variadas formas, com ou sem intenções de engajamento político e social, a Soweto. Se até 1994, ano das primeiras eleições democráticas na África do Sul, $56 \%$ dos visitantes justificavam a visita ao país remetendo aos atrativos naturais da região, com o fim do apartheid, Soweto passou à quarta posição na lista das atrações mais populares do país (RAMCHANDER, 2004). A localidade, assim como no caso da favela carioca, se estabeleceu como destino para turistas estrangeiros sem que qualquer marketing oficial fosse feito nesse sentido. A bem da verdade, durante os primeiros anos do regime democrático, o turismo nas townships enfrentou uma publicidade adversa que remetia ao estigma - ainda presente, é bom lembrar - que associa os bairros majoritariamente negros à violência e à miséria (RAMCHANDER, 2007).

Os passeios a Soweto são promovidos por diferentes agências que seguem basicamente a mesma estrutura, com variações que dependem menos da agência em questão e mais das relações que os próprios guias turísticos têm com os moradores. Assim como está previsto para acontecer após as obras do PAC na 
Rocinha ${ }^{20}$, em Soweto há um grande número de bed \& breakfast (hospedagem e café da manhã), administrado pelos residentes e que hoje conta com apoio do poder público.

\section{Para concluir}

Antropólogo e turista vão à procura do Outro guiados pela promessa da aventura e dos desafios postos pela alteridade. "No curso da história", observa Galani-Moutafi (1999), "colonialismo, missões religiosas, pesquisa etnográfica e turismo têm oferecido escapes poderosos para a busca da auto-representação; em face do individualismo, da mobilidade e da fragmentação - qualidades intrínsecas à modernidade - tal busca encontra motivação na nostalgia por uma comunidade ideal e completa" (p. 20, tradução nossa). A possibilidade da revelação de si através do encontro com "a comunidade" onde permaneceria resguardada "a cultura autêntica" é, como buscamos demonstrar, um elemento fundamental na composição da pobreza turística. É nessa

"fixação na autenticidade", nos termos de Sennett (1998) nessa "paixão pelo real" de que nos fala Badiou (2002), que experiências turísticas como as que acompanhamos aqui encontram motivação e legitimidade (FREIRE-MEDEIROS, 2007a).
Mas, como discutido por MacCannel (1973), Cohen (1988), Urry (1990), Baretto (2003) entre outros, a autencidade turística depende de como se apresenta e se percebe uma determinada localidade ou artefato, de que valores singulares os turistas acreditam-nos encarnados e dos princípios estéticos que são mobilizados para sua expressão. É nesse sentido que Cohen (1988) sugere 0 conceito de "autenticidade emergente": turistas atribuem autenticidade, por exemplo, a souvenirs e manifestações culturais encenadas não por ignorância, mas porque os tomam como símbolos que resumem 0 local visitado.

A cidade que se revela pelo contato com seus territórios marginais, quer na América do Sul ou na África, é percebida pelos turistas como real porque autêntica. Dito de outro modo, o que parece mobilizar aqueles que visitam Soweto e Rocinha não é simplesmente a vontade de conhecer esses territórios - repletos de singularidades dificilmente generalizáveis -, mas sim a aspiração de entrar em contato com aquela que seria a cidade real. Esta cidade verdadeira lhes parece estar por trás, às margens ou ir além da cidade cartão-postal que tantas vezes é encenada para os "gringos".

20 Em janeiro de 2007, o governador Sérgio Cabral anunciou um grande projeto de intervenção urbanística na Rocinha. Com orçamento previsto de R 72 milhões, o projeto inclui, além de melhorias na infra-estrutura e novos equipamentos urbanos, a transformação de residências na parte alta do morro em pousadas do tipo bed \& breakfast. Desde 2005 três pousadas localizadas em diferentes favelas da Zona Sul carioca já vêm hospedando turistas, em sua maioria, estrangeiros. A Pousada Favelinha (Morro do Pereirão) e The Maze Inn (Favela Tavares Bastos) possuem quartos com banheiros individuais e varandas com vistas privilegiadas para pontos turísticos do Rio. Já o empreendimento denominado Favela Receptiva (Vila Canoas) envolve uma rede de hospedagem domiciliar que credencia moradores da favela para que sejam "anfitriões" de turistas vindos de todas as partes do mundo. Hoje, este sistema de bed \& breakfast na favela conta com a participação de 20 famílias. 
Mas entrar em contato com a "cidade real" significa também colocar-se diante de um modo de vida tão diferente que estranhamento e ansiedade não podem ser evitados. As contradições que marcam a realidade das favelas cariocas e das townships lhes causam uma espécie de choque cognitivo: muitas vezes parecem descrentes diante do que os olhos vêem, incapazes de inteligir uma cidade supostamente mais contraditória e complexa do que seus locais de origem.

A análise dos travelblogs parece revelar que, independente da motivação que os tenha lavado a consumir a pobreza turística, no turista fica a sensação de ter vivido uma experiência de cidade inalcançável não apenas aos turistas convencionais, mas igualmente às elites autóctones. Uma experiência, portanto, duplamente transformadora: por um lado, tornamse mais conscientes do seu lugar no mundo; por outro, passam a ter uma "percepção real" da cidade visitada que fazem questão de registrar e compartilhar em suas memórias virtuais.

\section{Referências bibliográficas}

BARRETTO, M. 0 imprescindível aporte das ciências sociais para o planejamento e a compreensão do turismo. Horizontes antropológicos, Porto Alegre, vol. 9. n. 20 , oct. 2003.

BADIOU, A. Pequeno manual de inestética. São Paulo: Estação Liberdade, 2002.

BAUMAN, Z. Community: seeking safety in an insecure world. London: Polity Press, 2001.
BOURDIEU, P. A distinção: crítica social do julgamento. São Paulo: Edusp; Porto Alegre: Zouk, 2007.

CANCLINI, N. G. Consumidores e cidadãos: conflitos multiculturais da globalização. 4. ed. Rio de Janeiro: UFRJ, 1999 .

CARNEIRO, S.; FREIRE-MEDEIROS, B. Antropologia, religião e turismo: múltiplas interfaces. Religião \& sociedade, Rio de Janeiro: Instituto de Estudos da Religião (ISER), vol.24, n.2, 2004.

CARVALHO, Rose Meire. Janelas do ciberespaço: comunicação e cibercultura. Porto Alegre: Sulina, 2001 CHRISTOPHER, A.J. Apartheid planning in South Africa: the case of Port Elizabeth. In: Geographical journal, Oxford: Blackweel Publishing, n.153, p. 195-204, 1987.

CLIFFORD, J. Introduction: partial truths. In: ; MARCUS, George (eds.).Writing culture: the poetics and politics of ethnography. Berkeley: University of California Press, 1986, p. 1-26.

COHEN, E. Authenticity and commoditisation in tourism, Annals of tourism research, London. V.15, n.3, 371-386, 1988.

CRAWSHAW, C.; URRY, J. Tourism and the photographic eye. In: ROJEK, Chris; URRY, Jonhh. Touring cultures, transformations of travel and theory. London: Routledge, 1997, 176-195.

DA-RIN, Silvio. Espelho partido: tradição e transformação do documentário cinematográfico. Rio de Janeiro: Azougue, 2004.

DEBORD, G. A sociedade do espetáculo. São Paulo: Coletivo Periferia, 2003.

FEATHERSTONE, M. Cultura de consumo e pósmodernismo. São Paulo: Studio Nobel, 1995.

FIRTH, R. Introduction, Second Introduction. In: Malinowski, B. A diary in the strict sense of the term. Califórnia: Stanford University Press, 1989, 3-28. 
FREIRE-MEDEIROS, B. A favela que se vê e que se vende: Reflexões e polêmicas em torno de um destino turístico. Revista brasileira de Ciências Sociais, São Paulo, v. 22, p. 61-72, 2007a.

A favela e seus trânsitos turísticos. Revista do Observatório de Inovação do Turismo.Rio de Janeiro, v. 2, 2007b. Disponível em: <http://www. ebape.fgv.br/revistaoit/> Acesso em: 17 ago. 2008. Caridade ou curiosidade? Uma história cultural da assistência aos pobres na Londres vitoriana. Estudos históricos, Rio de Janeiro, n. 40, jul.-dez. 2007c.

; MENEZES, P.; NUNES, F. Ética, estética e consumos possíveis: Notas etnográficas sobre turismo em uma favela carioca. In: 0s urbanitas - Revista de Antropologia Urbana, São Paulo, ano 5, vol.5, n.7 Disponível em <http://www.osurbanitas.org/> Acesso em: 25 ago. 2008.

GALANI-MOUTAFI, V. The self and the other: Traveler, ethnographer, tourist. Annals of tourism research, London, v 27, n 1, pp. 203-224, 1999.

GEERTZ, C. Do Ponto de Vista do Nativo: a natureza do entendimento antropológico. In: Geertz,C.

0 saber local: novos ensaios em antropologia interpretativa. Tradução: Vera Mello Joscelyne. Petrópolis: Vozes, 1997.

GOUDIE. A.S.; Livingstone, I.; Stokes, S. Aeolian environments, sediments and landforms.0xford: Blackwell Publishing, 1999.

GIDDENS, A. The consequences of modernity. Stanford: Stanford University Press, 1991.

HALNON, K. B. Poor chic: the rational consumption of poverty. Current Sociology, London, vol. 50, n. 4, p. 501-516, 2002.

HUTNYK, J. The rumour of Calcutta: tourism, charity and a the poverty of representation. London, New Jersey: Zed Books, 1996.
ILLOUZ, E. Consuming the romantic utopia.

Berkeley: University of California Press, 1997.

MACCANNEL, D. Staged authenticity: arrangements of social space in tourist settings. American journal of Sociology, Chicago: University of Chicago Press, vol. 79, p. 589-603, 1973.

MABOGANE, M.; CALLAGHAN, R. Swinging safaris in Soweto. Johanesburgo, 2002. Disponível em: <http:// www.mg.co.za/mg/africa/soweto.html> Acesso em: 28 jul. 2008

MALINOWSKI, B. A diary in the strict sense of the term. California: Stanford University Press, 1989.

MÁXIMO, M. E. 0 eu encena, o eu em rede: um estudo etnográfico nos blogs. Civitas, Porto Alegre, v. 7 n. 2, p. 25-47, jul.-dez. 2007.

MENEZES, P. Gringos e câmeras na favela da Rocinha. 2007. Monografia (Bacharelado) Departamento de Ciências Sociais, Universidade do Estado do Rio de Janeiro, Rio de Janeiro, 2007.

PARNELL, S. Race, power and urban control: Johannesburg's inner city slum yards, 1910-1923. Journal of Southern African studies, London: Routledge, n. 29, v.3, p. 615-637, 2003.

RAMCHANDER, P. Soweto set to lure tourists. In: Bennett, A. and George, r. (eds.) South African travel and tourism cases. Pretoria: Van Schaik, 2004. Township tourism - blessing or blight? The case of Soweto in South Africa. In: Richards, G. (ed.) Cultural tourism: global and local perspectives. Binghamton, NY., The Haworth Hospitality Press, 2007.

SCHITTINE, D. Blog: comunicação e escrita intima na internet. Rio de Janeiro Ed. Civilização Brasileira, 2004.

SENNETT, R. 0 declínio do homem público: tiranias da intimidade. São Paulo: Companhia das Letras, 1998. 
STONE, P.R. A dark tourism spectrum: towards a typology of death and macabre related tourist sites, attractions and exhibitions. Tourism: an interdisciplinary international journal, Preston, v. 52, n.2 p. 145-160, 2006. Disponível em: < http:// pages.123-reg.co.uk/pstone1-995478/dark-tourism.org/ id38.html> Acesso em: 01 ago. 2008.

; SHARPLEY, R. Consuming Dark Tourism: a thanatalogical perspective. Annals of tourism research, London, n.35, v.2, p. 574-595, 2008.

URRY, J. 0 olhar do turista: lazer e viagens nas sociedades contemporâneas. São Paulo: Nobel, 1990.

Consuming places. London: Routledge, 1995.

ZELIZER, V. Culture and consumption. In: N SMELSNER, N.; SWEDBERG, R. (eds.). Handbook of Economic Sociology, Princeton: Princeton Univ. Press, 2004.

The purchase of intimacy.

Princeton: Princeton Univ. Press, 2007. 


\section{Diaries in the irrestrict sense of the term: virtua memories of real cities}

\section{Abstract}

Impoverished and segregated territories have been globally converted into tourist attractions eliciting ethical debates around the association between leisure and poverty. Many tourists who consume the touristic poverty do not ignore these debates and publicize their reflections on such experience through their travelblogs. This article examines the imagetic and discursive aspects of four blogs which present narratives about the experience of contact with the touristic poverty in Rocinha (Rio de Janeiro, Brazil) and Soweto (Johannesburg, South Africa). The broader aim is to show the impacts that such touristic experience has upon the image of the city produced by those tourists.

\section{Keywords}

Tourism. Poverty. Travelblogs. Rocinha. Soweto.

\section{Diarios en el sentido irrestricto del término: memorias virtuales de ciudades reales}

\section{Resumen}

La promoción de viajes a sitios asociados con la pobreza en diversas partes del mundo se ha tornado un negocio lucrativo que provoca debates éticos acerca de la asociación entre recreación y miseria. Muchos turistas que consumen la pobreza como atracción turística no ignoran esos debates y hacen públicas sus reflexiones sobre el tema en los travelblogs. Este artículo examina los aspectos imaginarios y discursivos de cuatro blogs que narran experiencias de contacto con la pobreza turística en la favela de la Rocinha (Rio de Janeiro, Brasil) y Soweto (Joanesburgo, África del Sur). El objetivo más amplio es mostrar los impactos que la experiencia del turismo en localidades pobres genera en la imagen de ciudad que los turistas producen.

\section{Palabras clave}

Turismo. Pobreza. Travelblogs. Rocinha. Soweto. 


\section{Expediente}

A revista E-Compós é a publicação científica em formato eletrônico da Associação Nacional dos Programas de Pós-Graduação em Comunicação (Compós). Lançada em 2004, tem como principal finalidade difundir a produção acadêmica de pesquisadores da área de Comunicação, inseridos em instituições do Brasil e do exterior.
E-COMPÓS I www.e-compos.org.br I E-ISSN 1808-2599

Revista da Associação Nacional dos Programas de Pós-Graduação em Comunicação. Brasília, v.11, n.1, jan./abr. 2008.

A identificação das edições, a partir de 2008, passa a ser volume anual com três números.

\section{CONSELHO EDITORIAL}

\section{Afonso Albuquerque}

Universidade Federal Fluminense, Brasil

Alberto Carlos Augusto Klein

Universidade Estadual de Londrina, Brasi

Alex Fernando Teixeira Primo

Universidade Federal do Rio Grande do Sul, Brasi

Alfredo Vizeu

Universidade Federal de Pernambuco, Brasil

Ana Carolina Damboriarena Escosteguy

Pontifícia Universidade Católica do Rio Grande do Sul, Brasil

Ana Silvia Lopes Davi Médola

Universidade Estadual Paulista, Brasil

André Luiz Martins Lemos

Universidade Federal da Bahia, Brasil

Ângela Freire Prysthon

Universidade Federal de Pernambuco, Brasil

Antônio Fausto Neto

Universidade do Vale do Rio dos Sinos, Brasil

Antonio Carlos Hohlfeldt

Pontifícia Universidade Católica do Rio Grande do Sul, Brasil

Arlindo Ribeiro Machado

Universidade de São Paulo, Brasil

César Geraldo Guimarães

Universidade Federal de Minas Gerais, Brasi

Cristiane Freitas Gutfreind

Pontifícia Universidade Católica do Rio Grande do Sul, Brasil

Denilson Lopes

Universidade Federal do Rio de Janeiro, Brasil

Eduardo Peñuela Cañizal

Universidade Paulista, Brasil

Erick Felinto de Oliveira

Universidade do Estado do Rio de Janeiro, Brasil

Francisco Menezes Martins

Universidade Tuiuti do Paraná, Brasil

Gelson Santana

Universidade Anhembi/Morumbi, Brasil

Hector Ospina

Universidad de Manizales, Colômbia

leda Tucherman

Universidade Federal do Rio de Janeiro, Brasil

Itania Maria Mota Gomes

Universidade Federal da Bahia, Brasil

Janice Caiafa

Universidade Federal do Rio de Janeiro, Brasil

Jeder Silveira Janotti Junior

Universidade Federal da Bahia, Brasil
John DH Downing

University of Texas at Austin, Estados Unidos

José Luiz Aidar Prado

Pontifícia Universidade Católica de São Paulo, Brasil

José Luiz Warren Jardim Gomes Braga

Universidade do Vale do Rio dos Sinos, Brasi

Juremir Machado da Silva

Pontifícia Universidade Católica do Rio Grande do Sul, Brasil

Lorraine Leu

University of Bristol, Grã-Bretanha

Luiz Claudio Martino

Universidade de Brasília, Brasil

Maria Immacolata Vassallo de Lopes

Universidade de São Paulo, Brasil

Maria Lucia Santaella

Pontifícia Universidade Católica de São Paulo, Brasil

Mauro Pereira Porto

Tulane University, Estados Unidos

Muniz Sodre de Araujo Cabral

Universidade Federal do Rio de Janeiro, Brasil

Nilda Aparecida Jacks

Universidade Federal do Rio Grande do Sul, Brasil

Paulo Roberto Gibaldi Vaz

Universidade Federal do Rio de Janeiro, Brasil

Renato Cordeiro Gomes

Pontifícia Universidade Católica do Rio de Janeiro, Brasil

Ronaldo George Helal

Universidade do Estado do Rio de Janeiro, Brasil

Rosana de Lima Soares

Universidade de São Paulo, Brasil

Rossana Reguillo

Instituto Tecnológico y de Estudios Superiores do Occidente, México

Rousiley Celi Moreira Maia

Universidade Federal de Minas Gerais, Brasil

Sebastião Carlos de Morais Squirra

Universidade Metodista de São Paulo, Brasil

Simone Maria Andrade Pereira de Sá

Universidade Federal Fluminense, Brasil

Suzete Venturelli

Universidade de Brasília, Brasil

Valério Cruz Brittos

Universidade do Vale do Rio dos Sinos, Brasil

Veneza Mayora Ronsini

Universidade Federal de Santa Maria, Brasil

Vera Regina Veiga França

Universidade Federal de Minas Gerais, Brasil

\section{COMISSÃO EDITORIAL}

Ana Gruszynski I Universidade Federal do Rio Grande do Sul, Brasil João Freire Filho I Universidade Federal do Rio de Janeiro, Brasil Rose Melo Rocha I Escola Superior de Propaganda e Marketing, Brasil

\section{CONSULTORES AD HOC}

Bianca Freire-Medeiros I Fundação Getulio Vargas, Brasil Josimey Costa da Silva I Universidade Federal do Rio Grande do Norte, Brasil Maria Conceição Golobovante I Pontifícia Universidade Católica de São Paulo, Brasil Marlyvan Moraes de Alencar I Centro Universitário SENAC-SP, Brasil Miriam de Souza Rossini I Universidade Federal do Rio Grande do Sul, Brasil Paulo Ribeiro I Pontifícia Universidade Católica do Rio de Janeiro, Brasil Rita Alves de Oliveira I Centro Universitário SENAC, Brasil

REVISÃO DE TEXTO E TRADUÇÃO I Everton Cardoso ASSISTÊNCIA EDITORIAL E EDITORAÇÃO ELETRÔNICA I Raquel Castedo
COMPóS I www.compos.org.br

Associação Nacional dos Programas de Pós-Graduação em Comunicação

Presidente

Erick Felinto de Oliveira

Universidade do Estado do Rio de Janeiro, Brasil erickfelinto@uol.com.br

Vice-presidente

Ana Silvia Lopes Davi Médola

Universidade Estadual Paulista, Brasil

asilvia@faac.unesp.br

Secretária-Geral

Denize Correa Araújo

Universidade Tuiuti do Paraná, Brasil

denizearaujo@hotmail.com 